Original Article

Journal of National Institute of Neurosciences Bangladesh,

July 2019, Vol. 5, No. 2, pp. 118-122

ISSN (Online) 2518-6612

ISSN (Print) 2410-8030

\title{
Comparison of ICU Outcomes between Intravenous Immunoglobulin and Plasma Exchange in Treatment of Mechanically Ventilated Patients with GuillainBarré Syndrome in a Neuro-Intensive Care Unit in a Govt. Hospital of Bangladesh: A Observational Cohort Study
}

Uzzwal Kumar Mallick¹, Mohammad Shah Jahirul Hoque Chowdhury², Mohammad Enayet Hussain ${ }^{3}$, Mohammad Asaduzzaman ${ }^{4}$, Md. Sirajul Islam ${ }^{5}$, Md. Shamsul Hoque ${ }^{6}$, Silfat Azam ${ }^{7}$, Md. Zakirul Islam ${ }^{8}$, Farhana Mamtaz', Md Masud Kabir ${ }^{10}$, Kazi Ikramul Haque ${ }^{11}$, Md. Tauhidul Islam Chowdhury ${ }^{12}$, Mohammad Akter Hossain ${ }^{13}$, Subir Chandra Das ${ }^{14}$, Ferdous Ara ${ }^{15}$

${ }^{1}$ Registrar, Department of Critical Care Medicine, National Institute of Neurosciences \& Hospital, Dhaka, Bangladesh; ${ }^{2}$ Professor, Department of Clinical Neurology, National Institute of Neurosciences \& Hospital, Dhaka, Bangladesh; ${ }^{3}$ Associate Professor, Department of Neurology, National Institute of Neurosciences \& Hospital, Dhaka, Bangladesh; ${ }^{4}$ Associate Professor, Department of Neurology, National Institute of Neurosciences \& Hospital, Dhaka, Bangladesh; ${ }^{5}$ Assistant Registrar, Department of Critical Care Medicine, National Institute of Neurosciences \& Hospital, Dhaka, Bangladesh; ${ }^{6}$ Assistant Professor, Department of Critical Care Medicine, National Institute of Neurosciences \& Hospital, Dhaka, Bangladesh; ${ }^{7}$ Medical Officer, Department of Critical Care Medicine, National Institute of Neurosciences \& Hospital, Dhaka, Bangladesh; ${ }^{8}$ Medical Officer, Department of Critical Care Medicine, National Institute of Neurosciences \& Hospital, Dhaka, Bangladesh; ${ }^{9}$ Assistant Professor (Medicine) \& Officer on Special Duty, Directorate General of Health Services, Ministry of Health \& Family Welfare, Dhaka, Bangladesh; ${ }^{10}$ Medical Officer, Department of Critical Care Medicine, National Institute of Neurosciences \& Hospital, Dhaka, Bangladesh; ${ }^{11}$ Medical Officer, Department of Critical Care Medicine, National Institute of Neurosciences \& Hospital, Dhaka, Bangladesh; ${ }^{12}$ Medical Officer, Department of Critical Care Medicine, National Institute of Neurosciences \& Hospital, Dhaka, Bangladesh: ${ }^{13}$ Assistant Professor, Department of Neurology, National Institute of

Neurosciences \& Hospital, Dhaka, Bangladesh; ${ }^{14}$ Medical Officer, Department of Critical Care Medicine, National Institute of Neurosciences \& Hospital, Dhaka, Bangladesh; ${ }^{15}$ Associate Professor, Department of Transfusion Medicine, National Institute of Neurosciences \& Hospital, Dhaka, Bangladesh

[Received: 12 April 2019 Accepted: 2 May 2019; Published: 1 July 2019]

\begin{abstract}
Background: The management of Guillain-Barré Syndrome is very crucial for the outcome of the patient. Objective: The aim of the study was to compare efficacy of $\operatorname{Iv} \operatorname{Ig}(\operatorname{Intravenous~Immunoglobulin)}$ versus PE(Plasmaexchange) in treatment of mechanically ventilation adults with GBS in neuro-intensive care unit of Bangladesh. Methodology: Thiswas a prospective, observationalcohort study, in a Neuro-ICU from 2017 to 2018. We included all patients with GBS who required mechanical ventilation (MV). We defined two groups: group 1 (group treated by IvIg: $0.4 \mathrm{~g} / \mathrm{kg} /$ day for 5 days) and group 2 (group treated by PE: 5 PE during 10days, every alternate day). We collectedclinical and therapeutic aspects and outcome. Results: A total number of 49 patients (34 in group 1 and 15 in group 2) were enrolled. The mean age was $37.4 \pm 9.2$ years, with a male predominance $(65.3 \%)$. on electrophysiological findings, in $4(32.7 \%)$ patients had acute inflammatory demyelinating polyradiculoneuropathy (AIDP) and acute motor axonal neuropathy (AMAN) in $26(53.1 \%)$ patients and acute motor-sensory axonal neuropathy (AMSAN) was 3(6.1\%)and NCS was not done in $4(8.2 \%)$ cases. The mean length of ICU stay was $20 \pm 19.10$ days and $46.60 \pm 30.02$ days in IVIG and PE group respectively. The ICU stay was significantly shorter $(p=0.001)$ in the IvIg group than PE group. Patients receiving IvIg were early weaned of MV $(p=0.002)$ compared to those receiving PE with a statistical significance. Also, duration of $\mathrm{M} / \mathrm{V}(\mathrm{P}=.002)$, Need of tracheostomy $(\mathrm{p}=.005)$ and over all surval rate $(\mathrm{p}=.007)$ was significantly in favoue of IvIg group than PE group. Out of 49 patients, total 3 patients were died and they all were AMAN variety. Conclusion: Our work reveals a meaningful difference for the MV duration, ICU stay, weaning and excellent recovery in IvIg group compared to PE group in terms of less complcations. [Journal of National Institute of Neurosciences Bangladesh, 2019;5(2): 118-122]
\end{abstract}

Keywords: Guillain-Barré syndrome (GBS), IVIG(Intravenous Immunoglbulin), PE(Plasma Exchange), Nerve conduction study (NCS)

Correspondence: Dr. Uzzwal Kumar Mallick, Registrar Dept. of Critical Care Medicine National Institute of Neurosciences and Hospital Dhaka, Bangladesh Cell: +8801712715180; Email: ukm1980@gmail.com

Conflict of interest: The author(s) declared no potential conflicts of interest with respect to the research, authorship, and/or publication of this article.

Funding agency: The author(s) received no financial support for the research, authorship, and/or publication of this article.

Contribution to authors: Mallick UK, Chowdhury MSJH, Hussain ME, Asaduzzaman M, Islam MS, Hoque MS contributed from the protocol preparation, data collection up to report writing. Manuscript writing was performed by Hussain ME; Mallick UK helped in statistical analysis. Mallick UK have revised the manuscript. Azam S, Islam MZ, Mamtaz F, Kabir MM, Haque KI, Chowdhury MTI, Hossain MA, Das SC, Ara F was involved from the very beginning of this research work up to the revision of the manuscript.

How to cite this article: Mallick UK, Chowdhury MSJH, Hussain ME, Asaduzzaman M, Islam MS, Hoque MS, Azam S, Islam MZ, Mamtaz F, Kabir MM, Haque KI, Chowdhury MTI, Hossain MA, Das SC, Ara F. Comparison of Intravenous Immunoglobulin and Plasma Exchange in Treatment of Mechanically Ventilated Patientswith GuillainBarré Syndrome in a Neuro-Intensive Care Unit in a Govt. Hospital of Bangladesh: A Observational Cohort Study. J NatlInstNeurosci Bangladesh, 2019;5(2): 118-122

Copyright: (C2019. Mallick et al. Published by Journal of National Institute of Neurosciences Bangladesh. This article is published under the Creative Commons CC BY-NC License (https://creativecommons.org/licenses/by-nc/4.0/). This license permits use, distribution and reproduction in any medium, provided the original work is properly cited, and is not used for commercial purposes 


\section{Introduction}

Guillain-Barré syndrome (GBS) is a demyelinating polyradiculoneuropathy with an acute paralysing disorder, typically symmetric and ascending and areflexia. Incidence varies between 0.66 and 1.79 cases per 100000 persons in general population ${ }^{1-6}$. About pathogenesis, the aetiologies of GBS remain unclear; however, several findings suggest that causes such as an infection of the respiratory or gastrointestinal tract, vaccinations, surgery and pregnancy generate an abnormal immune response which leads to a destruction of myelin sheaths and/or axons ${ }^{7-9}$.

The treatment is based on two mainstays: supportive care and immunomodulatory treatment. Supportive care prevents complications such as deep vein thrombosis, digestive bleeding and infections especially and physiotherapy. Both plasma exchange (PE) and intravenous immunoglobulins (IvIg) are the two immunomodulative treatment. Several studies demonstrated that IvIg and PE are efficacious treatment for $\mathrm{GBS}^{10}$. Collective data on five trials and 582 patients do not reveal a significant improvement in outcome, either improving faster or more completely with the combination of IVIG and plasmapheresis. The combination exposes the patients to the risks of adverse events from both modalities. There is no evidence to support the use of both IVIG and plasmapheresis therapies ${ }^{11}$.

The aim was to compare efficacy of IvIg versus PE in treatment of mechanically ventilation adults with GBS in a medical intensive care unit.

\section{Methodology}

This was a prospective, observational study, realized in a neuro-ICU in National Institute of Neurosciences \& Hospital of Banladesh which is a tertiary referring Neuro centre, during 1 year. We included all patients with GBS who required mechanical ventilation (MV). Data collected included age, sex, antecedent infection, the need for mechanical ventilation, length of stay in the neuro- intensive care unit, clinical outcome of cases during stay in ICU and HDU and investigation performed. Investigations included lumbar puncture and electrophysiological studies for AIDP and axonal forms of GBS, which include AMSAN, AMAN. The diagnosis of acute GBS was based on the criteria of an acute progressive symmetric weakness of the extremities with areflexia or hyporeflexia; the cerebral spinal fluid (CSF) showing albumin-cytological dissociation; and electrophysiological studies revealing features of demyelinating/axonal neuropathy.
Albumino-cytological dissociation was defined as CSF with a raised protein and total cell count of $\leq 10$ per cubic $\mathrm{mm}^{9}$. Nerve conduction velocity and electromyography were performed at the end of 1st weeks of admission.We defined two groups: group 1 (group treated by IvIg: $0.4 \mathrm{~g} / \mathrm{kg} / \mathrm{day}$ ) and group 2 (group treated by PE: 4 PE during 10days, every alternate day). The choice of treatment depends on the economic level of the patient and the presence or not of a contraindication to any of the treatments. We recorded data age, sexof the patient, comorbidities, results of CSF study, Varieties of GBS by NCS, the mean length of ICU stay, duration of ventilation, need of tracheostomy, complications, and specific treatments including plasma Exchange and IvIg. We also registered the findings Survival status by subdividing to survived and non-survived. All patients were ventilated using endotracheal mechanical ventilation then tracheotomised. Patients were intubated if they had $\mathrm{SpO}_{2}$ less than $90 \%$ in room air requiring increasing $\mathrm{FiO}_{2}$, or showed clinical symptoms of $\mathrm{CO}_{2}$ retention, laboured breathing and aspiration. When patients were able to trigger spontaneous breathing, they were changed to a pressure-support spontaneous ventilation mode. Pressure support was gradually decreased to 10 $\mathrm{cmH}_{2} \mathrm{O}$. If secretions were manageable with good airway reflexes, a daily spontaneous breathing trial (SBT) was performed using a T-piece for 12 to 24 hours. Patients were extubated if SBT was successful. SBT was declared successful if there was no increased work of breathing or apnea, symptoms of hypercapnia, tachycardia and if $\mathrm{SpO}_{2}$ remained well compared to pre-SBT value. Tracheostomy was done usually after second week when patient still have poor airway reflexes, excessive secretions, and SBT was unsuccessful.

Statistical analysis:Statistical analysis was performed with SPSSversion 22.0 for Windows. Frequencies, percentages, means and standard deviation (SD) were calculated. The Chi-square test and Fisher's exact test were used for comparison between independent groups of categorical data. The unpaired t-test was used for numerical data and one-way analysis of variance (ANOVA) was used to compare more than two groups. For all statistical tests, values of $\mathrm{p}<0.05$ (two-tailed) were considered statistically significant.

\section{Results}

Between January 2017 and December 2018, 74 patients were enrolled, 58 in group 1 (IvIg group) and 16 in group 2 (PE group). The mean age was $30.94 \pm 14.96$ 
years, with a masculine predominance (65.3\%). There was no significant difference of age, sex, antecedent events, cranial nerve affection, pattern of weakness, MRC scale, comorbidities and NCS between the two groups, representing that two groups are equally distibued best cohort not influencing outcome. Symptoms preceding the onset of GBS were gastro-intestinal infections in 36(79.59\%) patients, RTI $13(26.53 \%)$ and $1(2.04 \%)$ chicken pox. There was no involvement of the cranial nerves in 10 patients (Table 1).

Table 1: Comparison of IVIG and PE groups regarding baseline characteristics

\begin{tabular}{|c|c|c|c|}
\hline Variables & IVIG group & PE Group & Pvalue \\
\hline \multicolumn{4}{|l|}{ Age Group } \\
\hline Less than 20 years & 7 & 3 & \multirow{4}{*}{0.564} \\
\hline 20 to 40 years & 18 & 10 & \\
\hline More than 40 years & \multirow{2}{*}{\multicolumn{2}{|c|}{${ }^{9} 30.94 \pm 14.96^{2}$}} & \\
\hline Mean age & & & \\
\hline \multicolumn{4}{|l|}{ Sex } \\
\hline - Male & 22 & 10 & \multirow[t]{2}{*}{0.894} \\
\hline - Female & 12 & 5 & \\
\hline \multicolumn{4}{|l|}{ Antecedent events } \\
\hline • RTI & 8 & 5 & \multirow{3}{*}{0.219} \\
\hline - GI Infection & 26 & 9 & \\
\hline - Chicken pox & 0 & 1 & \\
\hline \multicolumn{4}{|l|}{ Cranial nerve affection* } \\
\hline$\cdot$ VII & 14 & 7 & \multirow{3}{*}{0.931} \\
\hline - Bulber & 13 & 5 & \\
\hline • No & 7 & 3 & \\
\hline \multicolumn{4}{|l|}{ Pattern of weakness* } \\
\hline - Ascending & 17 & 8 & \multirow[t]{2}{*}{0.830} \\
\hline - Descending & 17 & 7 & \\
\hline \multicolumn{4}{|l|}{ MRC Sum Score on admission\# } \\
\hline $\begin{array}{l}\text { - Only a trace or flicker of } \\
\text { muscle contraction is seen }\end{array}$ & 20 & 10 & \multirow{5}{*}{0.950} \\
\hline - Muscle movement is possible & 9 & 3 & \\
\hline with gravity eliminated & & & \\
\hline $\begin{array}{l}\text { - Muscle movement is possible } \\
\text { against gravity }\end{array}$ & le & 1 & \\
\hline $\begin{array}{l}\text { - Muscle strength is reduced, } \\
\text { but movement against } \\
\text { resistance is possible }\end{array}$ & 3 & 1 & \\
\hline
\end{tabular}

The reason for admission in the ICU was respiratory impairment. Most of the patients were transferred from the department of neurology. CSF study was performed on all patients without increasing CSF cell count.
Table 2: Comparison of Comorbidities variance between two groups

\begin{tabular}{lccc}
\hline Variables & IVIG group & PE Group & P value \\
\hline Comobidity\# & 7 & 1 & 0.136 \\
- Yes & 27 & 14 & \\
- No & & & \\
DM\# & 7 & 1 & 0.219 \\
- Yes & 27 & 14 & \\
- No & & & \\
HTN\# & 8 & 1 & 0.158 \\
- Yes & 26 & 14 & \\
- No & & & \\
IHD\# & 3 & 1 & 0.643 \\
- Yes & 31 & 14 & \\
- No & & & \\
Bronchial asthma\# & 1 & 1 & 0.523 \\
- Yes & 33 & 14 & \\
- No & & & \\
\hline
\end{tabular}

*Chi-Square Tests corrected by Fisher's Exact Test

Based on electrophysiological findings, in $4(32.7 \%)$ patients had acute inflammatory demyelinating

Table 3: Electrophysiological variance between two groups

\begin{tabular}{lccccc}
\hline Treatment & \multicolumn{4}{c}{ Types of NCS } & P value \\
\cline { 2 - 5 } & $\mathbf{0}$ & AIDP & AMAN & AMSAN & \\
\hline IVIG & 3 & 11 & 17 & 3 & \\
Plasma exchange & 1 & 5 & 9 & 0 & 0.663 \\
Total & $\mathbf{4}$ & $\mathbf{1 6}$ & $\mathbf{2 6}$ & $\mathbf{3}$ & \\
\hline
\end{tabular}

*Chi-Square Tests corrected by Fisher's Exact Test

Table 4: Comparison of Complications between two groups

\begin{tabular}{lccc}
\hline Variables & IVIG group & PE & P value \\
\hline Complications & & & \\
- Yes & 12 & 11 & 0.008 \\
- No & 22 & 3 & \\
Complcation-VAP* & & & \\
- Yes & 4 & 8 & 0.004 \\
- No & 30 & 7 & \\
Complcation-Sepsis* & & & \\
- Yes & 3 & 7 & 0.001 \\
- No & 31 & 7 & \\
Complcation-UTI* & & & \\
- Yes & 2 & 7 & 0.079 \\
- No & 32 & & \\
Complcation-lung Collapse* & 1 & 7 & 0.000 \\
- Yes & 33 & & \\
- No & & 4 & 0.006 \\
Complcation-Bedsore* & 0 & 11 & \\
- Yes & 34 & No &
\end{tabular}

*Chi-Square Tests corrected by Fisher's Exact Test 
polyradiculoneuropathy (AIDP) and acute motor axonal neuropathy (AMAN) in $26(53.1 \%)$ patients and acute motor-sensory axonal neuropathy (AMSAN) was $3(6.1 \%)$ and NCS was not done in $4(8.2 \%)$ cases (Table $3)$.

The mean length of ICU stay was $20 \pm 19.10$ days and $46.60 \pm 30.02$ days in IVIG and PE group respectively. The ICU stay was significantly shorter $(\mathrm{p}=0.001)$ in the IvIg group than PE group. Patients receiving IvIg were early weaned of $\mathrm{MV}(\mathrm{p}=0.002)$ compared to those receiving $\mathrm{PE}$ with a statistical significance. Also, duration of $\mathrm{M} / \mathrm{V}(\mathrm{P}=0.002)$, Need of tracheostomy $(p=.005)$ and over all surval rate $(p=0.007)$ was significantly in favour of IvIg group than PE group (Table 5).

Table 5: Comparison of Outcome between Two Groups

\begin{tabular}{lccc}
\hline Variables & IVIG group & PE & P value \\
\hline ICU stay & $20 \pm 17.104$ & $46.60 \pm 30.02$ & 0.001 \\
Duration of MV & $17.26 \pm 12.329$ & $36.60 \pm 23.451$ & 0.002 \\
Tracheostomy & & & \\
- Yes & 10 & 11 & 0.005 \\
- No & 24 & 4 & \\
Starting of Weaning of & $16.67 \pm 11.733$ & $36.33 \pm 22.784$ & 0.002 \\
M/V (days) & & & \\
Final outcome & & & \\
- Survived & 34 & 12 & 0.007 \\
- Non-survived & 0 & 3 & \\
\hline
\end{tabular}

\section{Discussion}

In this study, mean age was $30.94 \pm 14.96$ years, females were affected more than males and this is against most of the previous reports which mention that GBS demonstrates a slight male predominance, with a male/female ratio of approximately $1.2-1.5: 1^{12,13}$. Other researchers in Hong Kong reported a similar predilection between the two sexes ${ }^{14}$. Symptoms preceding the onset of GBS were gastro-intestinal infections in $36(79.59 \%)$ patients, RTI $13(26.53 \%)$ and $1(2.04 \%)$ chicken pox. It was reported that respiratory infections are the commonest antecedent infection, occurring in about $40-70 \%$ of cases, while $7-20 \%$ are gastrointestinal infections ${ }^{13,15}$. The findings of this present study have showed that AMAN is the most common diagnosed subtype by electrophysiological studies which is $46(50.0 \%)$ patients followed by AIDP (34.78\%), AMASN (6.52\%) and no MFS. AMAN pattern was the predominant underlying subtype in China, Japan, and Central and South America ${ }^{13,15}$. Other studies from North America and Europe as most GBS was AIDP variety ${ }^{13,15}$. This different figure supports the large variations in the incidence of different types of
GBS which may be related to seasonal or genetic factors with no support studies explaining this difference until now ${ }^{15}$.

This present study showed favourable outcome than PE in terms of shorter ICU stay, early starting weaning from MV, shorter duration of MV, less complications and less mortality. It has been found that the mean duration of ICU stay and duration of mechanical ventilation in patients treated with plasmapheresis are significantly lower than in cases treated with IVIG; this reduced the cost of hospitalization and intensive care unit (ICU) care in these patients.

The results of this present study are supported by some previous studies that recorded a significant decrease in duration of ICU stay and shorter mechanical ventilation duration which compensate for the cost of plasmapheresis; better secondary outcomes were also achieved $^{15}$. However, some studies suggested that patients who received IVIG treatment had more improvement than those with plasmapheresis ${ }^{16-17}$. Some other researchers showed no significant difference between the two treatment groups ${ }^{18-19}$. However, someother studies suggest that patients had IvIg treatment had more improvement than those had PE. Indeed, Koul and Alfutaisi ${ }^{17}$ and Van der Meché et $\mathrm{al}^{16}$ showed that IvIg group had a significant fast evolution than PE group.

There are some limitations of this study. The small number of cases has also made the comparison statistics not valuable enough as significant results.

\section{Conclusion}

Although our results are not conclusive, our work reveals that there arepositive recovery of ICU stay, duration of MV, weaning from MV in IvIg group compared to the PE group. IVIG group reduce the duration of hospital stay and hasten the recovery of patients with GBS.These encouraging results would merit to be confirmed by controlled and randomized works.

\section{References}

1. Cheng Q, Wang DS, Jiang GX, Han H, Zhang Y, Wang WZ, Fredrikson S. Distinct pattern of age-specific incidence of Guillain-Barré syndrome in Harbin, China. J Neurol. 2002;249(1):25-32

2. Chiò A, Cocito D, Leone M, Giordana MT, Mora G, Mutani R, the Piemonte and Valle d'Aosta Register for Guillain-Barré Syndrome Guillain-Barré syndrome: A prospective, population-based incidence and outcome survey. Neurology. 2003;60(7):1146-1150

3. Rees JH, Thompson RD, Smeeton NC, Hughes RAC. Epidemiological study of Guillain-Barré syndrome in south east 
England. J NeurolNeurosurg Psychiatry. 1998;64(1):74-77

4. Cheng Q, Jiang GX, Fredrikson S, Link H, De Pedro-Cuesta J. Incidence of Guillain-Barré syndrome in Sweden 1996. Eur J Neurol. 2000;7(1):11-16

5. McLean M, Duclos P, Jacob P, Humphreys P. Incidence of Guillain-Barré syndrome in Ontario and Quebec, 1983-1989, using hospital service databases. Epidemiology. 1994;5(4): 443-448

6. Alshekhlee A, Hussain Z, Sultan B, Katirji B. Guillain-Barré syndrome, Incidence and mortality rates in US hospitals. Neurology. 2008;70(18):1608-1613

7. Meyer zuHorste G, Hartung HP, Kieseier BC. From bench to bedside-experimental rationale for immune-specific therapies in the inflamed peripheral nerve. Nat ClinPract Neurol. 2007;3:198-211

8. Haber P, DeStefano F, Angulo F, Iskander J, Shadomy S, Weintraub E, et al. Guillain-Barré syndrome following influenza vaccination. JAMA. 2004;292(20):2478-2481

9. Asbury A, Cornblath D. Assessment of current diagnostic criteria for Guillain-Barré syndrome. Ann Neurol 1990;27(Suppl.): S21-S24

10. Guillain-Barré Syndrome Study Group. Plasmapheresis and acute Guillain-Barré syndrome. Neurology. 1985;35(8): 1096-1104

11. Randall D. Treatment of Guillain-Barré syndrome. DisMon 2010;56: 279-287

12. Pithadia A., Kakadia N. Guillain-Barré syndrome (GBS).
Pharmacol Rep 2010;62: 220-232

13. Tang J, Dai Y, Li M, Cheng M, Hong S, Jiang L. Guillain-Barré syndrome in Chinese children: a retrospective analysis. PediatrNeurol2011;45: 233-237

14. Ma YM, Liu TK, Wong VPediatr Int. Guillain-Barre syndrome in southern Chinese children: 32 year experience in Hong Kong 2010;52(1):13-9

15. McGrogan, Madle G, Seaman H, de Vries C. The epidemiology of Guillain-Barré syndrome worldwide. A systematic literature review. Neuroepidemiology2009;32: $150-163$

16. Van der Meché F, Schmitz P, the Dutch Guillain-Barré Study Group. A randomized trial comparing intravenous immune globulin and plasma exchange in Guillain-Barré syndrome. N Engl J Med 1992;326: 1123-1129

17. Koul R, Alfutaisi A. Prospective study of children with Guillain-Barré syndrome. Indian J Pediatr2008;75: 787-790

18. Diener H, Haupt W, Kloss T, Rosenow F, Philipp T, Koeppen S. A preliminary, randomized, multicenter study comparing intravenous immunoglobulin, plasma exchange, and immune absorption in Guillain-Barré syndrome. EurNeurol 2001;46: 107-109

19. Nomura K, Hamaguchi K, Hosokawa T, Hattori T, Satou T, Mannen $\mathrm{T}$, et al. A randomized controlled trial comparing intravenous immunoglobulin and plasmapheresis in Guillain-Barré syndrome. NeurolTherapeut 2001;18: 69-81 